\title{
Experimental investigation of the performance of palm kernel shell and periwinkle shell as partial replacement for coarse aggregate in asphaltic concrete
}

\author{
Oyedepo $0 J^{*}$ and Olukanni EO
}

\author{
Department of Civil and Environmental Engineering, Federal University of Technology Akure, Nigeria. \\ * Corresponding Author: oyedepoo@yahoo.co.uk
}

\begin{abstract}
Performance of non-conventional materials namely palm kernel shell (PKS) and periwinkle shell (PWS) were investigated. Sieve analysis, aggregate impact value (AIV), aggregate crushing value (ACV), bitumen penetration, Marshall Stability, flash and fire point were carried out in accordance with American Standard for Materials and Testing (ASTM) and British Standard (BS) specifications. A total of thirty-six samples were prepared by partially replacing coarse aggregate with PKS and PWS at $0 \%, 10 \%, 20 \%, 30 \%, 40 \%$ and $50 \%$. The AIV and ACV values of $35.85 \%$ and $11.49 \%$ were obtained for PWS, while $6.42 \%$ and $9.22 \%$ respectively were obtained for PKS; this is usable for wearing course. The $10 \%$ partial replacement with PWS has Marshall Stability value of $2.33 \mathrm{kN} ; 10 \%$ and $20 \%$ partial replacement with PKS has Marshall Stability values of $3.0 \mathrm{kN}$ and $2.2 \mathrm{kN}$ respectively, while $10 \%, 20 \%$ and $30 \%$ partial replacement with combination of PWS and PKS has Marshall Stability values of $3.22 \mathrm{kN}, 2.41 \mathrm{kN}$ and $2.21 \mathrm{kN}$ respectively; thus satisfying the requirement for light traffic road. Also, $10 \%$ and $20 \%$ partial replacement with the combination of PWS and PKS gives a flow value of $8.9 \mathrm{~mm}$ and $8.5 \mathrm{~mm}$ which can be used for light traffic. Hence, $10 \%$ to $20 \%$ partial replacement of coarse aggregate with PWS and PKS can be used as alternative material in asphaltic concrete to reduce the cost of construction.
\end{abstract}

Key words: Palm Kernel, Periwinkle, Asphalt, Aggregate, Traffic.

\section{Introduction}

Significant increases in axle loads have increase stress induced on road surface and thus increase in maintenance which has been a challenge on road pavement operation. Factors such as durability, strength and economic needs have to be considered in the design and construction of road pavement. Therefore, road paving industry is interested in utilizing alternative and sustainable materials that will satisfy aforementioned needs and aid in the production, placement, and performance of road pavement.

Asphaltic concrete is a combination of binder, filler, coarse aggregate and fine aggregate which are blended in a specific ratio to get the required quality and provide a smooth driving surface to vehicles and bikes while driving and braking on the highway. The demand for more roads, increasing expense of production of asphaltic blend and shortage of naturally occurring materials being utilized has required the quest for alternative and manageable materials that will fulfill the previously stated needs and help in the production and use of asphalts. Additionally, growth in population, expanding urbanization and rising ways of life due to technological advancements have added to increment in the amount of solid waste generated by modern, mining, local and farming exercises. Nwaobakata and Agunwamba (2014) researched the utilization of biomaterials and agro-waste specifically is a subject of extraordinary intrigue these days not just from the innovative and logical perspectives, additionally socially, and financially, as far as work, expense and natural issues. Therefore, this research examines the execution of palm kernel shell (PKS) and periwinkle shell (PWS) as incomplete substitution for coarse aggregate in asphaltic cement. 


\subsection{Overview of Properties Palm Kernel Shell}

Palm kernel shell (PKS) is the hard endocarp of palm kernel natural product that encompasses the palm kernel seed of the oil palm tree (Elaeisguineensis) (Abiola, 2006). The palm kernel tree is local of West Africa and broadly spread all through the tropics. It develops to around 9 meter in height and characterized with a crown of fluffy leaves that are over $5 \mathrm{~mm}$ long. PKS comprises of little size particles, medium size particles and substantial size particles in the extent 0-5 mm, 5-10 $\mathrm{mm}$ and 10-15 mm (Alengaram, 2010). It is evaluated that the PKS constitutes around $34.5 \%$ of a single ripe, fresh fruit, (Aragbaiye, 2007). PKS's are derivable in expansive amounts; the shells have no commercial value, yet constitute major natural issues.

\subsection{Overview of Properties Periwinkle Shell}

Periwinkle has been described by Badmus et al. (2007) as small marine snails with spiral cone, shaped shells having a round opening and dull interior. The major species reported by Beredugo (1984), to be available in the lagoon and mudflats of Nigeria's Niger Delta, between Calabar in the east and Badagry in the west, are Tympanostomus spp and Pachmellania spp. A survey by Umoh and Olusola (2012) discovered that large quantities of periwinkle shells are available in many riverine communities of the South-South geopolitical region of Nigeria. Most periwinkles are edible, the fleshy (edible) parts are usually removed after boiling in water, and the shells are usually discarded. Continuous dumping of the discarded part has become a serious source of land pollution in areas where they are found. Accordingly, Dahunsi and Bamisaye (2002) reported that large quantities of periwinkle shells have accumulated in many parts of the country such as Warri, Western Ijaw, Burutu, Ogoni, Ogalaga and Lotughene of the Niger delta of Nigeria.

\section{Materials and methodology utilized for evaluation}

\subsection{Materials}

The materials utilized for this research work were chosen carefully to meet with standard requirement of materials utilized as a part of asphaltic cement; these are as filler, bitumen, coarse aggregates, fine aggregates, periwinkle shell (PWS) and palm kernel shell (PKS).

Fine and Coarse Aggregates: The fine aggregates in Figure 1 is a finely chosen river sand free from deleterious material got from Irese town in Ondo state. The coarse aggregates passing through 19-12mm sieve in Figure 2 and filler were acquired from Simbo quarry, Aye in Ondo state. The coarse aggregates were painstakingly chosen to conform with the required specification and free from deleterious materials. Additionally, 70/80 penetration grade bitumen was acquired from Sapelle in Delta State Nigeria.

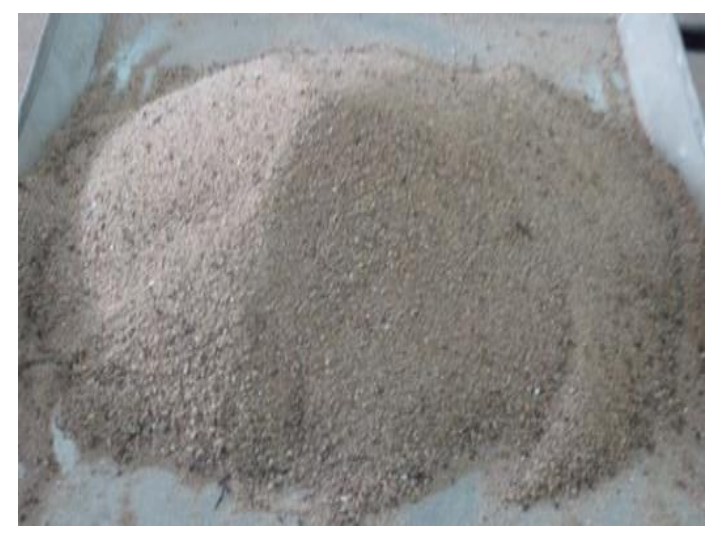

Fig 1. Fine aggregate

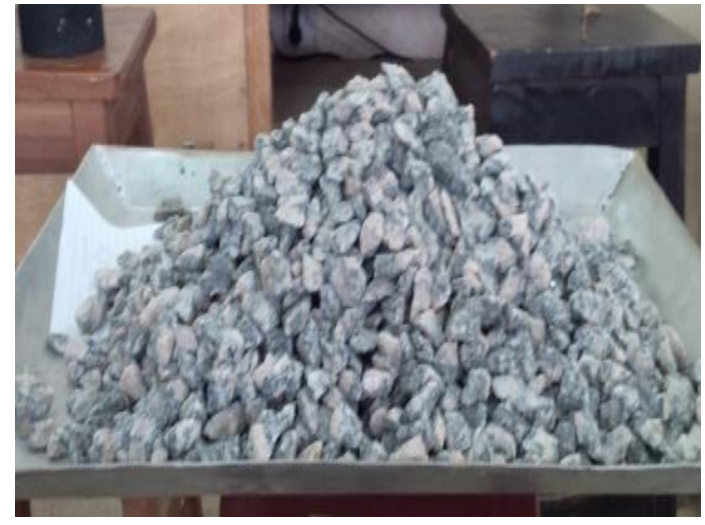

Fig 2. Coarse aggregates

Periwinkle and Palm Kernel Shell: The precisely chose PWS shown in Figure 3 was gotten from Rumuji town, Emohua Local Government Area in Port-harcout, River State. The carefully 
selected PKS in Figure 4 was acquired from Engr. Akinjo's farm situated at Oke-Ijebu in Akure, Ondo State Nigeria.

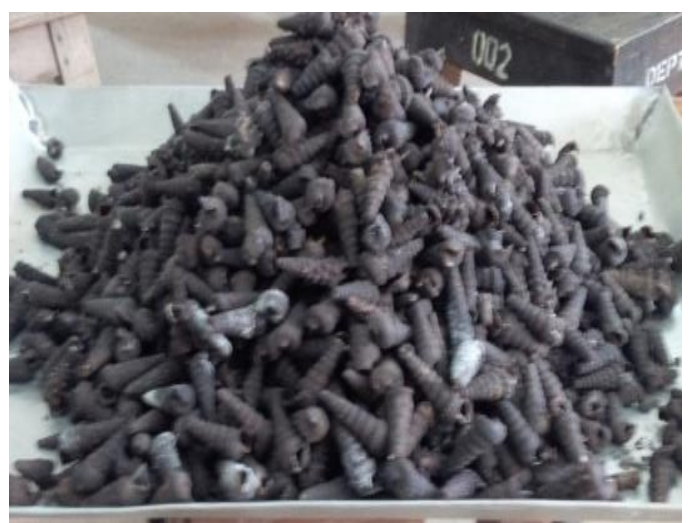

Fig 3. Periwinkle shell

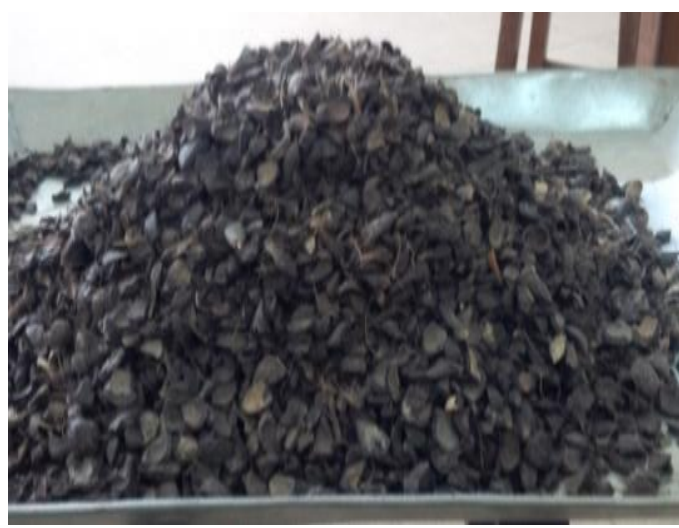

Fig 4. Palm kernel shell

\subsection{Methods}

Specified proportions of each material such as $4 \%$ filler of size $0.075 \mathrm{~mm}, 6 \%$ quarry dust of maximum size $5 \mathrm{~mm}, 66 \%$ river sand of maximum size $5 \mathrm{~mm}$ and $28 \%$ coarse aggregate of size 5 $16 \mathrm{~mm}$ with $6 \%$ bitumen of penetration grade $70 / 80$ was mixed together at $150^{\circ} \mathrm{C}$. The mixture was compacted with 50 blows both at the top and bottom to obtain cylindrical samples for the Marshall Stability test. PKS were partially replaced at $0 \%, 10 \%, 20 \%, 30 \%, 40 \%$ and $50 \%$ by weight of total coarse aggregate in the mixture. Three samples each shown in Figures 5 and 6 were prepared for each percentage replacement of coarse aggregate with PKS and PWS. Same procedure was repeated for PWS to replace coarse aggregate, however, a total of thirty-six samples were prepared for both PKS and PWS for the study.

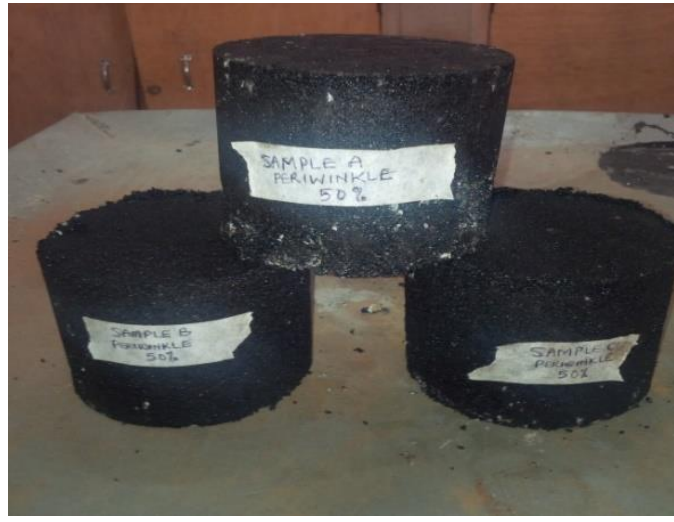

Fig 5. Marshall stability test specimen (PKS)

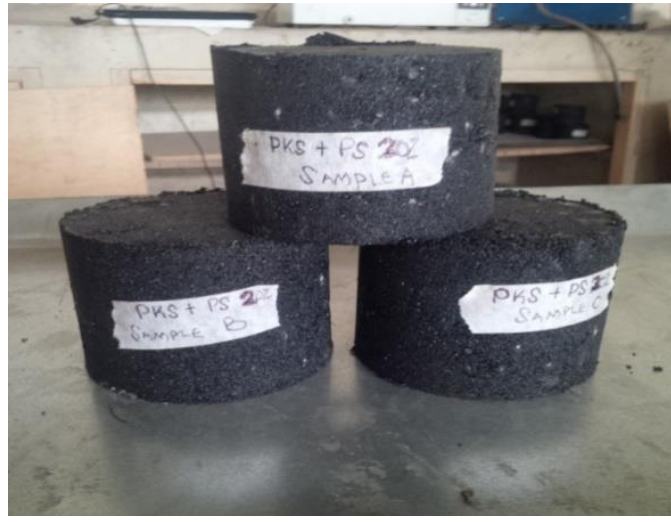

Fig 6. Marshall stability test specimen (PWS)

Several tests were performed in accordance to the standard specifications as follows:

- Sieve Analysis (ASTM C136-06, 2006).

- $\quad$ Aggregate Impact Value (AIV) Test (BS 812-112, 1990).

- $\quad$ Aggregate Crushing Value (ACV) Test (BS 812-110, 1990).

- Specific Gravity Test (ASTM C127-12, 2012) and (ASTM C128-12, 2012) for coarse and fine aggregates respectively.

- Bitumen Penetration Test (BS 2000-487, 2009).

- Marshall Stability Test (ASTM D6927-06, 2006).

- Moisture Content Test (Dean and Stark Method). 
- Flash and Fire Point Test.

\section{Results and Discussion}

Figure 7 shows the particle size distribution curve of PKS and PWS, FA and CA aggregates respectively, which are carried out in accordance with ASTM C136/C136M.

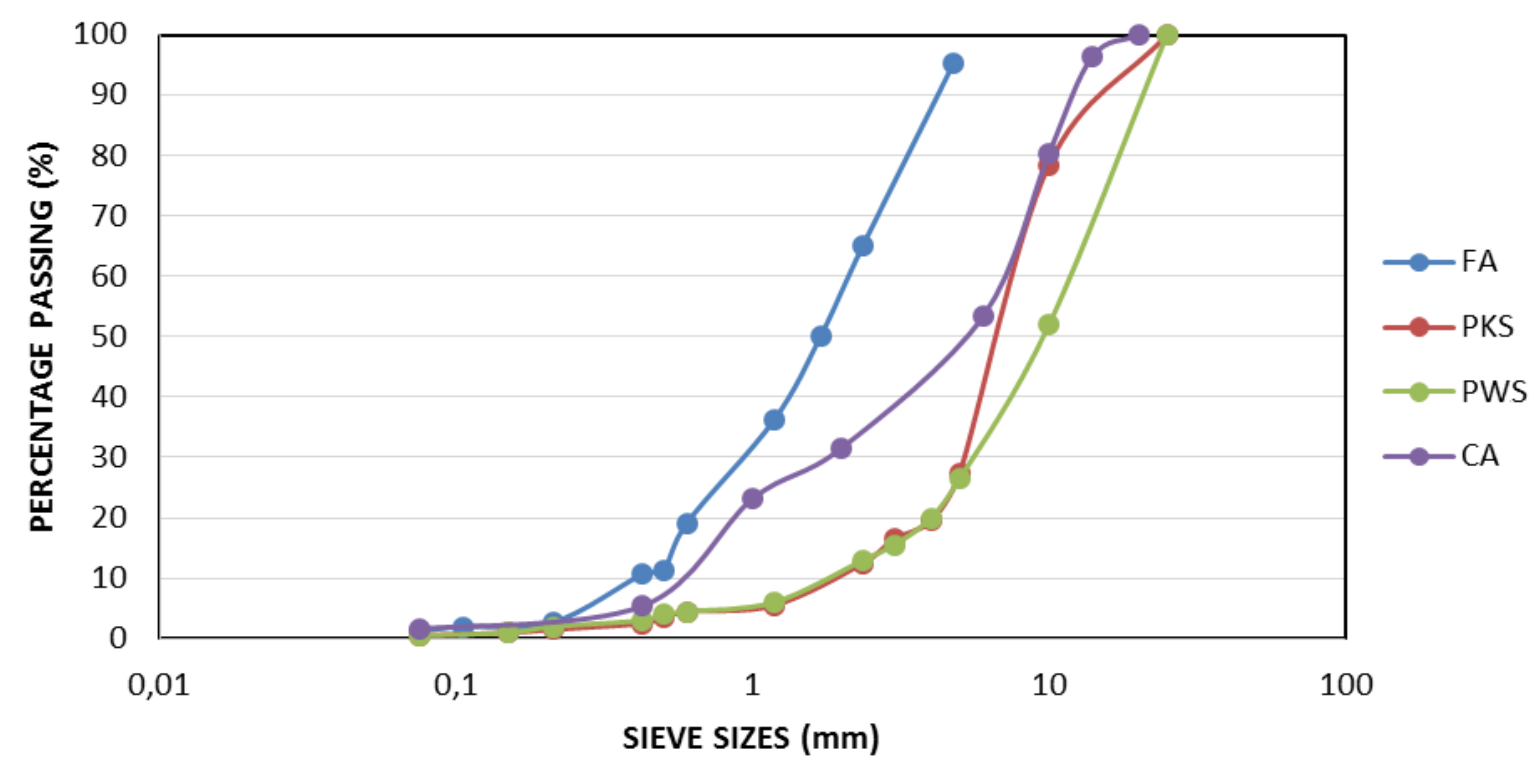

Fig 7. Particle grading curves of palm kernel shell (PKS), periwinkle shell (PWS), fine aggregate (FA) and coarse aggregate (CA).

\section{From the curves:}

\section{$\mathrm{C}_{\mathrm{u}}$ and $\mathrm{C}_{\mathrm{c}}$ for PKS}

$\mathrm{D}_{10}=1.964 \mathrm{~mm}, \mathrm{D}_{30}=5.245 \mathrm{~mm}, \mathrm{D}_{60}=8.186 \mathrm{~mm}$

$C_{u}=\frac{D_{60}}{D_{10}}=\frac{8.186}{1.964}=4.17 ; \quad C_{c}=\frac{\left(D_{30}\right)^{2}}{D_{10} D_{60}}=\frac{5.245^{2}}{1.964 \times 8.186}=1.71$

Where:

$D_{60}$ is the particle diameter, at which 60 percent by weight of the soil is finer,

$\mathrm{D}_{30}$ is particle diameter, at which 30 percent by weight of the soil is finer,

$\mathrm{D}_{10}$ is particle diameter, at which 10 percent by weight of the soil is finer,

$\mathrm{C}_{\mathrm{u}}$ is the coefficient of uniformity and $\mathrm{C}_{\mathrm{c}}$ is the coefficient of curvature.

Note: For a gravel to be classified as well graded, $\mathrm{C}_{\mathrm{u}}>4 \& 1<\mathrm{C}_{\mathrm{c}}<3$; thus, the PKS used is well graded since the $\mathrm{C}_{\mathrm{u}}$ is 4.17 , i.e. more than 4 .

Similarly, the $\mathrm{C}_{\mathrm{u}}$ and $C_{c}$ for PWS, FA and CA were calculated in the same manner.

\section{$\mathrm{C}_{\mathrm{u}}$ and $\boldsymbol{C}_{\boldsymbol{c}}$ for PWS}

$\mathrm{D}_{10}=1.956 \mathrm{~mm}, \mathrm{D}_{30}=5.755 \mathrm{~mm}, \mathrm{D}_{60}=12.562 \mathrm{~mm}, \mathrm{C}_{\mathrm{u}}=6.42$ and $\mathrm{C}_{\mathrm{c}}=1.35$

For a gravel to be classified as well graded, $\mathrm{C}_{\mathrm{u}}>4 \& 1<\mathrm{C}_{\mathrm{c}}<3$; thus, the $\mathrm{C}_{\mathrm{u}}$ value obtained for PWS shows that it is well graded.

\section{$\mathrm{C}_{\mathrm{u}}$ and $C_{c}$ for, FA}

$\mathrm{D}_{10}=0.425 \mathrm{~mm}, \mathrm{D}_{30}=1.18 \mathrm{~mm}, \mathrm{D}_{60}=2.1 \mathrm{~mm}, \mathrm{C}_{\mathrm{u}}=4.94$ and $\mathrm{C}_{\mathrm{c}}=1.56$;

For a sand to be classified as well graded the $\mathrm{C}_{\mathrm{u}}>4$ and $1<\mathrm{C}_{\mathrm{c}}<3$; thus, the value obtained indicate that the fine aggregate is well graded. 


\section{$\mathrm{C}_{\mathrm{u}}$ and $C_{c}$ for CA}

$\mathrm{D}_{10}=0.574 \mathrm{~mm}, \mathrm{D}_{30}=1.706 \mathrm{~mm}, \mathrm{D}_{60}=6.978 \mathrm{~mm}, \mathrm{C}_{\mathrm{u}}=12.16$ and $\mathrm{C}_{\mathrm{c}}=0.73$. The $\mathrm{C}_{\mathrm{u}}$ value of coarse aggregate showed that it is well graded.

Tables 1 presents the summary of results of various tests carried out on the materials, while Table 2 is the summary of Marshall Stability test. However, Figures 8 and 9 show plot of Stability versus Composition and Flow versus Percentage Composition respectively.

Table 1. Summary of test results.

\begin{tabular}{|c|c|c|c|c|c|}
\hline $\mathrm{S} / \mathrm{N}$ & Properties & $\begin{array}{c}\text { Results } \\
\text { Obtained }\end{array}$ & \multicolumn{2}{|c|}{ Recommended Standard } & Remarks \\
\hline 1 & $\begin{array}{l}\text { Los Angeles } \\
\text { Abrasion Test }\end{array}$ & $\begin{array}{c}\mathrm{CA}=27.5 \% \\
\mathrm{PWS}=2 \\
\mathrm{PKS}=27.5 \%\end{array}$ & \multicolumn{2}{|c|}{$\begin{array}{l}\text { Max. Limit for Bituminous concrete surface } \\
\text { coarse }(30 \%)\end{array}$} & $\begin{array}{c}\text { Satisfactory for } \\
\text { road } \\
\text { surfacing/wearing } \\
\text { course }\end{array}$ \\
\hline 2 & $\begin{array}{c}\text { Moisture Content } \\
\text { On Fine } \\
\text { Aggregate } \\
\end{array}$ & $2.10 \%$ & & & Satisfactory \\
\hline \multirow[b]{2}{*}{3} & & & $\begin{array}{c}\text { Specified Limit } \\
(\%)\end{array}$ & Toughness Properties & \\
\hline & $\begin{array}{l}\text { Aggregate Impact } \\
\text { Value Test }\end{array}$ & $\begin{array}{c}\mathrm{CA}=22.4 \% \\
\mathrm{PWS}=35.85 \% \\
\mathrm{PKS}=6.42 \%\end{array}$ & $\begin{array}{c}<10 \\
10-20 \\
20-30 \\
>35\end{array}$ & $\begin{array}{c}\text { Exceptionally tough / } \\
\text { Strong } \\
\text { Very tough / Strong } \\
\text { Good for pavement surface } \\
\text { course } \\
\text { Weak for pavement surface } \\
\text { course } \\
\end{array}$ & $\begin{array}{c}\text { Satisfactory for } \\
\text { road } \\
\text { surfacing/wearing } \\
\text { course }\end{array}$ \\
\hline & Aggregate & & \multicolumn{2}{|c|}{ Specified Limit (\%) } & \\
\hline 4 & $\begin{array}{l}\text { Crushing Value } \\
\text { Test }\end{array}$ & $\begin{array}{c}\mathrm{CA}=27.92 \% \\
\mathrm{PWS}=11.49 \% \\
\mathrm{PKS}=9.22 \%\end{array}$ & \multicolumn{2}{|c|}{$\begin{array}{c}\text { Not more than } 30 \% \text { for Surface or wearing } \\
\text { course }\end{array}$} & Satisfactory \\
\hline 5 & $\begin{array}{c}\text { Water In Bitumen } \\
\text { Test } \\
\end{array}$ & $3.9 \%$ & \multicolumn{2}{|c|}{ Max. Permissible is $5 \%$} & Satisfactory \\
\hline 6 & Penetration Test & 75.44 & & & \\
\hline 7 & $\begin{array}{l}\text { Flash Point Test } \\
\text { Fire Point Test }\end{array}$ & $\begin{array}{l}288 \\
326\end{array}$ & $\begin{array}{l}280-3000 \mathrm{C} \\
300-320 \mathrm{oC}\end{array}$ & & $\begin{array}{l}\text { Satisfactory } \\
\text { Satisfactory }\end{array}$ \\
\hline
\end{tabular}

Table 2. Summary of Marshall Stability test results.

\begin{tabular}{|c|c|c|c|c|c|c|}
\hline \multirow{2}{*}{$\begin{array}{c}\% \\
\text { Composition }\end{array}$} & \multicolumn{2}{|c|}{ PWS } & \multicolumn{2}{c|}{ PKS } & \multicolumn{2}{c|}{ PWS+PKS } \\
\cline { 2 - 7 } & Stability (kN) & Flow (mm) & Stability (kN) & Flow (mm) & Stability (kN) & Flow (mm) \\
\hline \hline 0 & 3.151 & 9.2 & 3.63 & 9.3 & 3.39 & 9.4 \\
\hline 10 & 2.33 & 8.1 & 3.08 & 8.4 & 3.22 & 8.9 \\
\hline 20 & 2.1 & 7.7 & 2.28 & 8.0 & 2.41 & 8.5 \\
\hline 30 & 1.63 & 4.5 & 1.92 & 4.85 & 2.21 & 7.9 \\
\hline 40 & 1.18 & 3.87 & 1.04 & 3.60 & 1.04 & 3.64 \\
\hline 50 & 1.105 & 4.50 & 1.01 & 4.8 & 0.70 & 4.6 \\
\hline
\end{tabular}

The AIV and ACV values of $35.85 \%$ and $11.49 \%$ were obtained for PWS, while $6.42 \%$ and $9.22 \%$ respectively were obtained for PKS as shown in Table 1; this indicate that it could be used for Surface or wearing course. Also, the moisture content of 3.9\% in bitumen showed that the value is absolutely small and can be easily burnt off during the production of Hot Mix Asphalt; an average penetration of bitumen used is 75.44 . The flash point of the bitumen of $288^{\circ} \mathrm{C}$ indicates that the bitumen could be used in the production of Hot Mix Asphalt. 


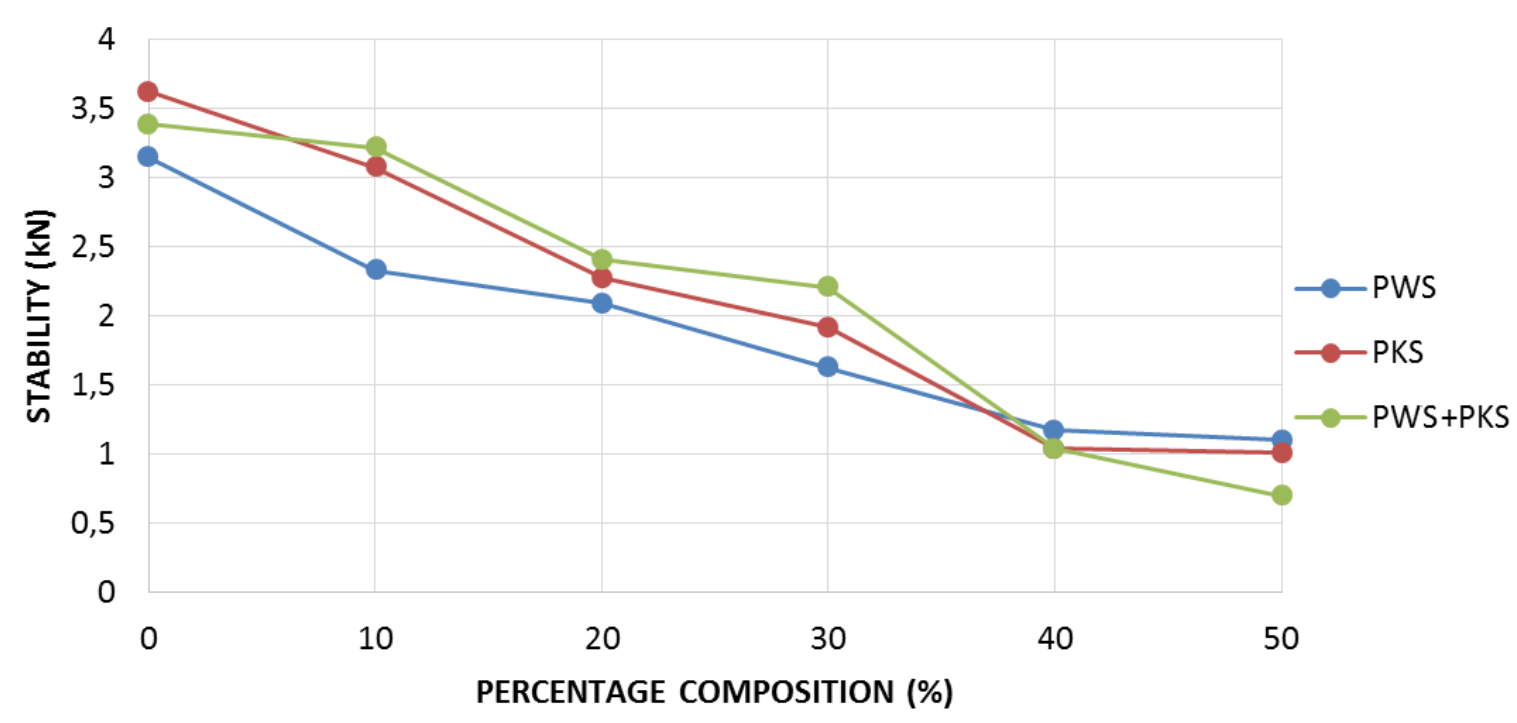

Fig 8. Graph of stability versus percentage composition.

The Marshall Design Criteria for Stability provided by the Asphalt Institute requires minimum values for different traffic classifications as:

- $\quad 2.223 \mathrm{kN}$ for Light Traffic.

- $\quad 3.336 \mathrm{kN}$ for Medium Traffic.

- $6.672 \mathrm{kN}$ for Heavy Traffic.

The 10\% partial replacement with PWS has $2.33 \mathrm{kN}$ which is more than the value stated for light traffic. Also, $10 \%$ and $20 \%$ partial replacement with PKS has stability values of $3.08 \%$ and $2.28 \%$ respectively, which is higher than the value designated for light traffic. However, $10 \%, 20 \%$ and $30 \%$ partial replacement with combination of PWS and PKS has Marshall Stability values of $3.22 \mathrm{kN}, 2.41 \mathrm{kN}$ and $2.21 \mathrm{kN}$ respectively, which satisfy the requirement for light traffic.

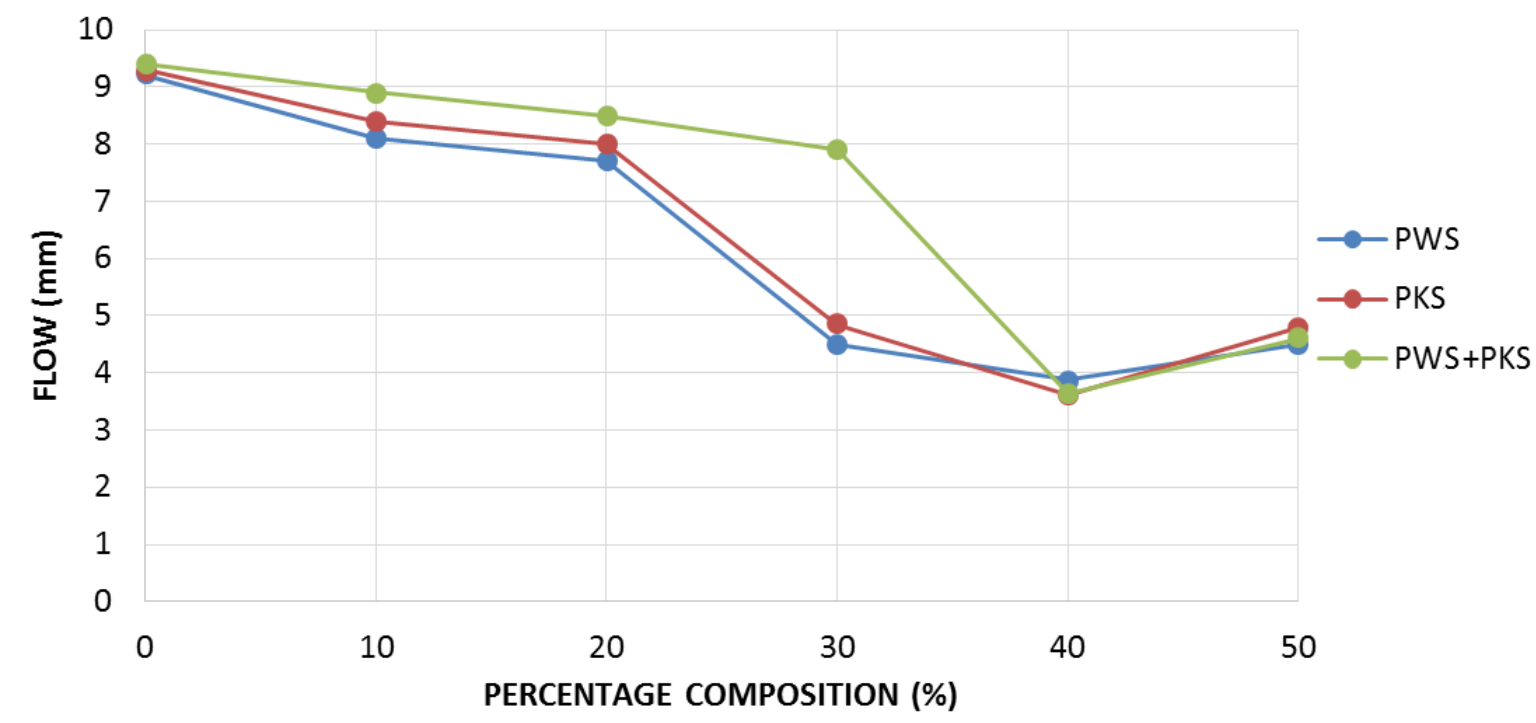

Fig 9. Graph of Flow versus Percentage Composition

The Marshall Design Criteria for flow at $0.25 \mathrm{~mm}$ provided by the Asphalt Institute for different traffic classifications are:

- $\quad 8-20 \mathrm{~mm}$ for Light Traffic.

- $\quad 8-18 \mathrm{~mm}$ for Medium Traffic. 
- $\quad 8$ - 16 mm for Heavy Traffic.

The results show that $10 \%$ partial replacement with PWS gives a flow value of $8.1 \mathrm{~mm}$ while, $10 \%$ and $20 \%$ partial replacement with PKS gives a flow value of $8.4 \mathrm{~mm}$ and $8.0 \mathrm{~mm}$ does satisfying light traffic requirement. However, $10 \%$ and $20 \%$ partial replacement with the combination of PWS and PKS gives a flow value of $8.9 \mathrm{~mm}$ and $8.5 \mathrm{~mm}$ which can be used for light traffic.

\section{Conclusion}

The AIV and ACV values of $35.85 \%$ and $11.49 \%$ were obtained for PWS, while $6.42 \%$ and $9.22 \%$ respectively were obtained for PKS indicating that it could be used for Surface or wearing course. The moisture content of $3.9 \%$ and flash point of the bitumen of $288^{\circ} \mathrm{C}$ showed that the bitumen can be used in the production of Hot Mix Asphalt.

In addition, the $10 \%$ partial replacement with PWS has $2.33 \mathrm{kN}$ which is more than the value stated for light traffic. Also, $10 \%$ and $20 \%$ partial replacement with PKS have stability values of $3.08 \mathrm{kN}$ and $2.28 \mathrm{kN}$ respectively, which is higher than the value designated for light traffic. However, 10\%, 20\% and 30\% partial replacement with combination of PWS and PKS have Marshall Stability values of $3.22 \mathrm{kN}, 2.41 \mathrm{kN}$ and $2.21 \mathrm{kN}$ respectively; thus, it satisfies the requirement for light traffic.

The results also show that $10 \%$ partial replacement with PWS gives a flow value of $8.1 \mathrm{~mm}$ while, $10 \%$ and $20 \%$ partial replacement with PKS give a flow value of $8.4 \mathrm{~mm}$ and $8.0 \mathrm{~mm}$ does satisfying light traffic requirement. However, $10 \%$ and $20 \%$ partial replacement with the combination of PWS and PKS give flow values of $8.9 \mathrm{~mm}$ and $8.5 \mathrm{~mm}$ which can be used for light traffic. Hence, $10 \%$ to $20 \%$ partial replacement of coarse aggregate with PWS and PKS can be used as alternative material for light traffic roads. It is therefore recommended that this agrobased product can be used as partial alternate material in asphaltic concrete to reduce the cost of construction

\section{References}

Abiola OM. (2006). Characteristics of palm kernel shells powder as additive in sandcrete. Transaction of the Nigeria Society of Engineers, 2(1), 21-32.

Adewuyi AP, Adegoke T. (2008). Exploratory study of periwinkle shells as coarse aggregates in concrete works. ARPN Journal of Engineering and Applied Sciences, 3(6), 1-5.

Agbede OI, Manasseh J. (2009). Suitability of periwinkle shell as partial replacement for river gravel in concrete. Leonardo Electronic Journal of Practices and Technologies, 8(15), 59-66.

Alengaram UJ, Mahmud H, Jumaat MZ, \& Shirazi SM. (2010). Effect of aggregate size and proportion on strength properties of palm kernel shell concrete. International Journal of the Physical Sciences, 5(12), 1848-1856.

Aragbaiye BA. (2007). Palm kernel shell as composite material in concrete. Unpublished B. Eng project report. Dept of Civil Engineering, University of Ilorin, Ilorin, 25-31.

ASTM C127-12 (2012). Standard test method for density, relative density (specific gravity), and absorption of coarse aggregate. ASTM International, West Conshohocken, PA.

ASTM C128-12 (2012). Standard test method for density, relative density (specific gravity), and absorption of fine aggregate, ASTM International, West Conshohocken, PA

ASTM C136-06. (2006). Standard test method for sieve analysis of fine and coarse aggregates. ASTM International, West Conshohocken, PA.

ASTM D6927-06 (2006). Standard test method for marshall stability and flow of bituminous mixtures, ASTM International, West Conshohocken, PA.

Badmus MAO, Audu TOK, Anyata BU. (2007). Removal of lead ion from industrial wastewaters by activated carbon prepared from periwinkle shells (Typanotonus fuscatus). Turkish Journal of Engineering and Environmental Science, 31(4), 251-263. 
Beredugo YO. (1984). Periwinkle shells as concrete aggregates. Nigerian Building and Road Research Institute, Federal Ministry of Education, Science and Technology.

BS 2000-487 (2009). Bitumen and Bituminous Binder: Determination of Penetration Power of Bituminous Emulsion. British Standard.

BS 812-110 (1990). Testing Aggregates Method for Determination of Aggregate Crushing Value (ACV). British Standard.

BS 812-112 (1990). Testing Aggregates Method for Determination of Aggregate Impact Value (AIV). British Standard.

Dahunsi BIO, Bamisaye JA. (2002). Use of periwinkle shell ash (PSA) as partial replacement for cement in concrete. In Proceedings of Nigerian Materials Congress and Meeting of Nigerian Materials Research Society, pp. 184-186.

Dahunsi BIO, Olufemi SA, Akinpelu M, Olafusi O S. (2013). Investigation of the properties of "pure water" sachet modified bitumen. Civil and Environmental Research, 3(2):47-61.

Edeh JE, Manasseh J, Ibanga U. (2012). Palm kernel shell ash stabilization of reclaimed asphalt pavements as highway pavement materials. Journal of Sustainable Development and Environmental Protection, 2(1):89-110.

Nwaobakata C, Agunwamba JC. (2014). Effect of palm kernel shells ash as filler on the mechanical properties of hot mix asphalt. Archives of Applied Science Research, 6(5):42-49.

Oyedepo OJ, Olanitori LM, Olukanni EO. (2015). Investigation of palm kernel shell as partial replacement for aggregate in asphaltic concrete. Malaysian Journal of Civil Engineering, 27(2):223-234.

Oyedepo OJ, Oluwajana SD. (2014). Evaluation of properties of bitumen modified with waste tyre. Nigerian Journal of Technology, 33(1), 119-124.

Umoh AA, \& Olusola KO. (2012). Effect of different sulphate types and concentrations on compressive strength of periwinkle shell ash blended cement concrete. International Journal of Engineering \& Technology, 12(5), 10-17. 